\title{
Hydrogen Separation Using Pt-Alumina Impregnated Membrane
}

\author{
Mohammed N. Kajama, Ngozi C. Nwogu, Edidiong O. Okon, Habiba Shehu, Ify Orakwe, \\ Edward Gobina \\ Centre for Process Integration and Membrane Technology, (CPIMT), School of Engineering, The Robert Gordon \\ University, Aberdeen, UK \\ Email: e.gobina@rgu.ac.uk
}

Received 18 June 2015; accepted 22 August 2015; published 25 August 2015

Copyright (C) 2015 by authors and Scientific Research Publishing Inc.

This work is licensed under the Creative Commons Attribution International License (CC BY). http://creativecommons.org/licenses/by/4.0/

(c) (i) Open Access

\begin{abstract}
A tubular commercial mesoporous support was used to prepare a Pt impregnated membrane using the reservoir method and tested for moderate temperature $\left(300^{\circ} \mathrm{C}\right)$ gas transport of hydrogen $\left(\mathrm{H}_{2}\right)$, helium (He) and nitrogen $\left(\mathrm{N}_{2}\right)$ gas molecules. $\mathrm{H}_{2}$ and $\mathrm{N}_{2}$ gas permeation of 6.1 and $4.5 \mathrm{l} / \mathrm{min}$ at 1.0 barg feed pressure and $25^{\circ} \mathrm{C}$ respectively was obtained from the support. On the other hand, $\mathrm{H}_{2}$ and $\mathrm{N}_{2}$ gas permeation of 4.6 and $1.7 \mathrm{l} / \mathrm{min}$ at $1.0 \mathrm{barg}$ feed pressure and $25^{\circ} \mathrm{C}$ respectively was also obtained from the Pt membrane. Selectivity of $\mathrm{H}_{2}$ over $\mathrm{He}$ of 1.96 at $300^{\circ} \mathrm{C}$ and 1.6 barg for the Pt membrane was obtained and found to be higher than that of the theoretical Knudsen selectivity. Also, a selectivity of $\mathrm{H}_{2}$ over $\mathrm{N}_{2}$ of 2.72 at $25^{\circ} \mathrm{C}$ and 1.0 barg was obtained and found to be close to that of the theoretical Knudsen selectivity. The gas permeation and the selectivity performance of the membrane were evaluated.
\end{abstract}

\section{Keywords}

Tubular Support, Pt Membrane, Hydrogen Selectivity, Permeation Temperature

\section{Introduction}

Hydrogen is extensively used in the chemical, oil refining, petro-chemical and steel industries and is also projected as the clean alternative source of energy [1]. Almost 50\% of the world's hydrogen is produced from fossil fuels, such as natural gas and naphtha through steam reforming reaction [1]. Literature shows that hydrogen can actually be separated using inorganic membranes [1]-[4]. Inorganic membranes derived from ceramics and metal alloys are candidates for high temperature gas separation. Palladium (Pd) [1] [5] and platinum (Pt) [5] alloys and metals are the ideal membranes applied for high purity hydrogen production from mixed gas streams even 
though these metals and their alloys are expensive. Pd-based membranes are attractive for membrane reactor applications because Pd is highly permeable to hydrogen and offer better thermal stability and selectivity than polymer and microporous membranes [5]. Transport of hydrogen through dense Pd membranes follows the solution diffusion mechanism where only hydrogen is transported resulting in high hydrogen purity (99.9999\%), but have been limited in commercialization due to issues which include support quality, surface poisoning due to carbon species, hydride formation, and irreversible damage caused by bulk sulfide formation [5]-[7].

The main characteristics of inorganic membranes are permeance and separation factor [8]. Permeance is a measure of the gas flow rate per unit area per unit pressure difference. Permeance is a more practical unit than permeability because the thickness of the membrane is not usually known very accurately [8]. Permeability is the permeance multiplied by the thickness of the membrane, and the selectivity is the ratio of the permeances.

The transport of gases through membranes is highly dependent on the pore diameter. Gas transport can also be affected by pressure and temperature. A change in temperature can affect the flow regime differently at different pore diameters. Hence, it is critically important to be able to follow the changes in the transport mechanisms of different gases during pore diameter reduction to help determine the extent to which pores have been modified [8].

Here, we examine the behaviour of gas permeation on a tubular commercial support and a Pt-alumina membrane, and their corresponding selectivity at different pressures and temperatures.

\section{Experimental}

Commercially available tubular alumina support was used. The support was a mesoporous (2 - $50 \mathrm{~nm})$. The support consisted of 7 and $10 \mathrm{~mm}$ internal and outer diameter respectively. The support possesses a permeable length of $348 \mathrm{~mm}$ and a porosity of $45 \%$. Scanning electron microscopy (Zeiss EVO LS10) image (not shown) and the energy diffraction X-ray analysis (EDAX) of the Pt membrane was obtained.

The Pt membrane was prepared using the following procedure. A solution of hexachloroplatinic acid $\left(\mathrm{H}_{2} \mathrm{PtCl}_{6}\right)$ was used as platinum precursor. The tubular support was first dried at $65^{\circ} \mathrm{C}$. After weighing, it was dipped for 2 hours in pure water before $\mathrm{H}_{2} \mathrm{PtCl}_{6}$ introduction. The deposition method used was based on evaporation-crystallisation steps using the method proposed by Uzio et al. [9]. The tube was first dipped for 2 hours in pure water (in our case we used deionised water) afterwards the tube was dipped for 10 hours in a $10 \mathrm{~g} / \mathrm{l}$ of $\mathrm{H}_{2} \mathrm{PtCl}_{6}$ solution. The sample was then dried at room temperature to favour evaporation from the inner side and deposition in the top layer.

\section{Results and Discussion}

Figure 1 depicts the EDAX analysis of the Pt membrane. The compositional result is also shown in Table 1. After Pt impregnation, it can be seen in Table 1 that a $3.52 \mathrm{wt} \% \mathrm{Pt}$ is obtained.

Figure 2 depicts the single gas permeation of $\mathrm{H}_{2}, \mathrm{He}$ and $\mathrm{N}_{2}$ for the support. The permeation of molecules

Table 1. EDAX analysis of the Pt membrane.

\begin{tabular}{ccc}
\hline Element & Weight (\%) & Atomic (\%) \\
\hline $\mathbf{C a C O}_{3}(\mathbf{C ~ K})$ & 14.41 & 19.64 \\
$\mathrm{SiO}_{2}(\mathbf{O}$ K) & 50.68 & 51.88 \\
$\mathrm{Al}_{2} \mathbf{O}_{3}(\mathbf{A l ~ K})$ & 38.52 & 23.38 \\
$\mathrm{SiO}_{2}(\mathrm{Si} \mathrm{K})$ & 0.28 & 0.16 \\
$\mathbf{K C l}(\mathbf{C l})$ & 3.28 & 1.51 \\
Wollastonite (Ca K) & 0.32 & 0.13 \\
Titanium (Ti K) & 7.94 & 2.72 \\
Zirconium (Zr L) & 1.61 & 0.29 \\
Platinum (Pt M) & 3.52 & 0.30 \\
\hline
\end{tabular}




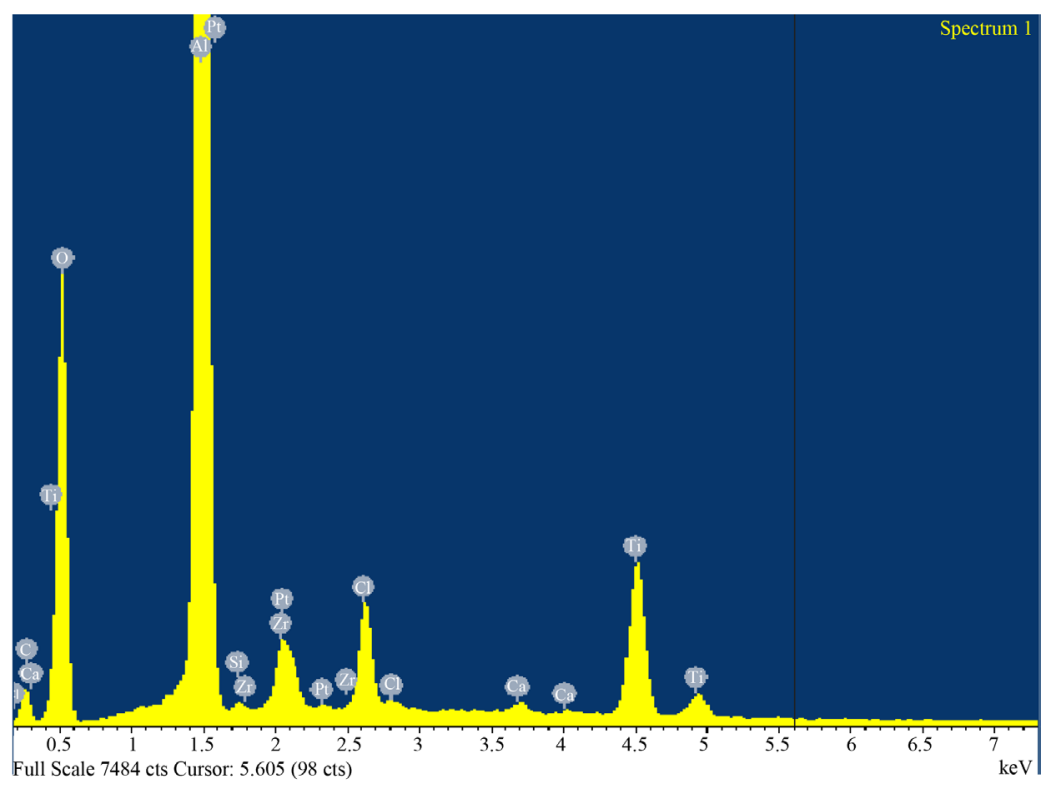

Figure 1. EDAX of the Pt membrane showing the outer surface.

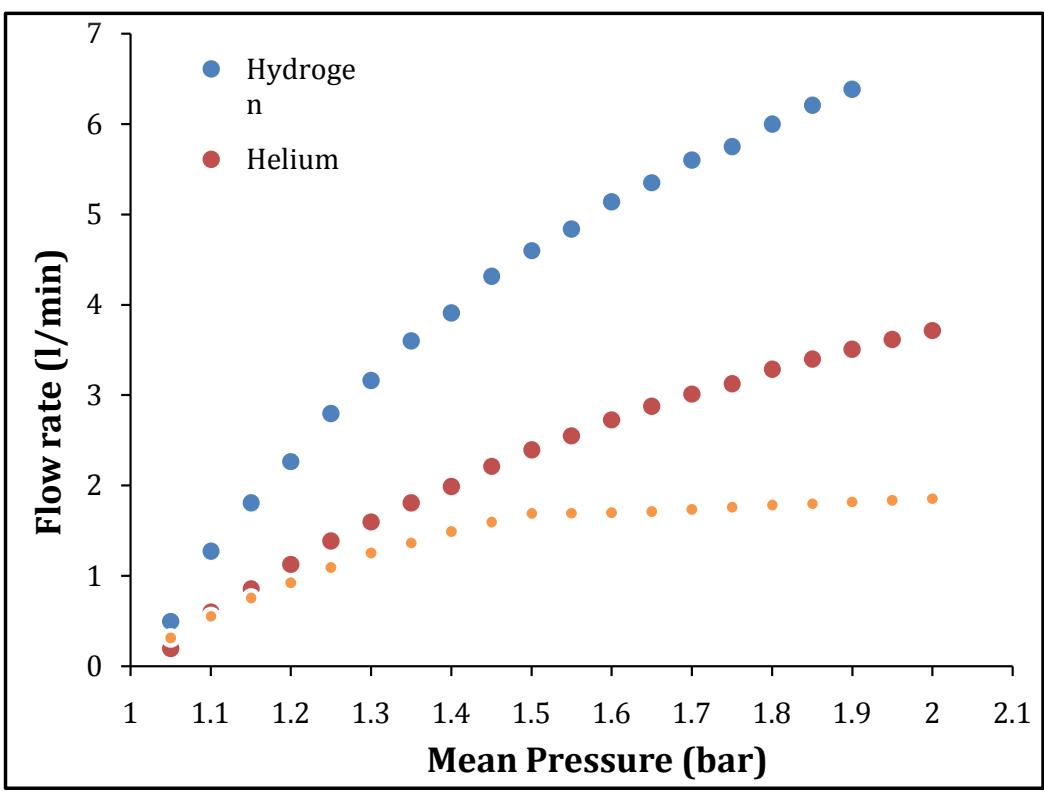

Figure 2. Gas permeation and mean pressure relationship at $25^{\circ} \mathrm{C}$.

with the smaller molecular weight such as $\mathrm{H}_{2}=2 \mathrm{~g} / \mathrm{mol}$ and $\mathrm{He}=4 \mathrm{~g} / \mathrm{mol}$ diffuses faster with pressure whilst the larger molecular weight $\mathrm{N}_{2}=28 \mathrm{~g} / \mathrm{mol}$ had low permeation. These results are indicative of Knudsen diffusion transport mechanism which states that the permeation flux is directly proportional to the inverse square root of the molecular weights of gases.

Figure 3 depicts the permeation $\mathrm{H}_{2}$ on the support and Pt membrane against feed pressure between 0.1 up to 1.0 barg. The results show a higher $\mathrm{H}_{2}$ permeation with respect to the support.

Figure 4 depicts the effect of temperature and permeation of $\mathrm{H}_{2}, \mathrm{He}$ and $\mathrm{N}_{2}$ on the support at temperatures between $25^{\circ} \mathrm{C}$ up to $300^{\circ} \mathrm{C}$ and 1.5 barg feed pressure. The permeation of molecules with smaller molecular weight such as $\mathrm{H}_{2}$ and He increase with temperature whilst the flux of larger molecule like $\mathrm{N}_{2}$ is independent of temperature. These results are indicative of Knudsen diffusion transport mechanism. Gopalakrishnan and Diniz da Costa [10] also observed a higher permeation rate for $\mathrm{He}$ and $\mathrm{H}_{2}$ at temperatures between $100^{\circ} \mathrm{C}$ up to $400^{\circ} \mathrm{C}$ 
on silica membrane.

The effect of temperature on $\mathrm{H}_{2} / \mathrm{He}$ single gas selectivity with temperatures between $25^{\circ} \mathrm{C}$ up to $300^{\circ} \mathrm{C}$ and 1.6 barg feed pressure on Pt membrane is depicted in Figure $5 . \mathrm{H}_{2}$ selectivity of 1.96 over helium was obtained at $300^{\circ} \mathrm{C}$ which is 2 fold to the theoretical knudsen selectivity. Also, an improvement of $\mathrm{H}_{2}$ selectivity is achieved as the temperature increased from $25^{\circ} \mathrm{C}$ to $300^{\circ} \mathrm{C}$. Figure 6 depicts $\mathrm{H}_{2} / \mathrm{N}_{2}$ selectivity and feed pressure relationship on the support and Pt membrane at $25^{\circ} \mathrm{C}$. It can be seen clearly that a selectivity of 1.36 and 2.72 were obtained from the support and Pt membrane. This result corroborates with the literature [11] on silica membrane. This is a clear indication that the Pt results in an activation of the hydrogen transport to enhance the selectivity of hydrogen.

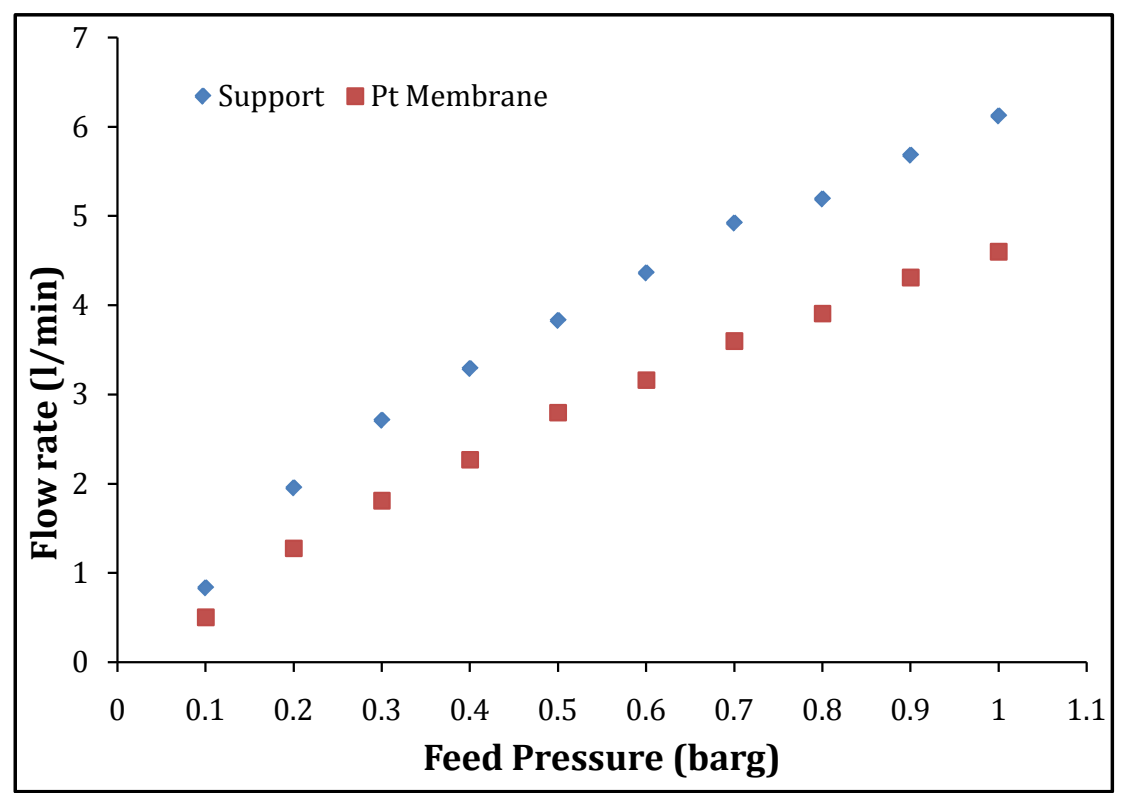

Figure 3. Hydrogen permeation Vs feed pressure of the support and Pt membrane at $25^{\circ} \mathrm{C}$.

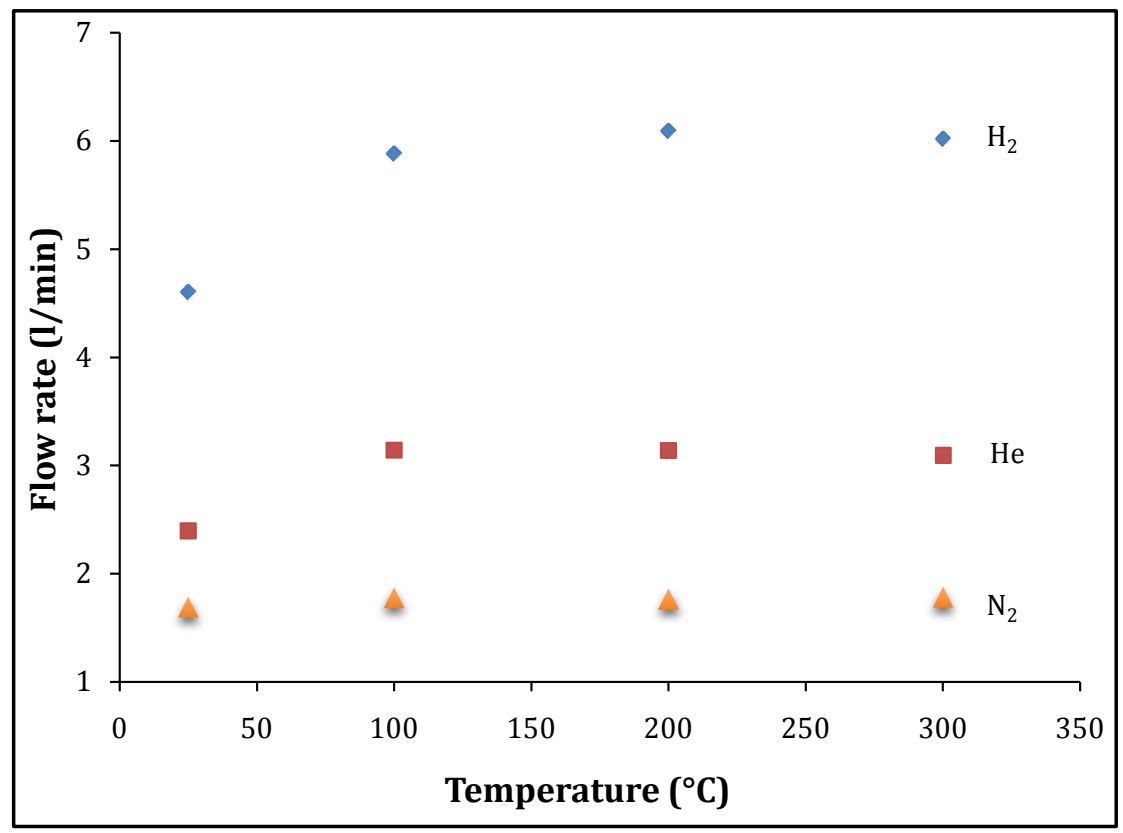

Figure 4. Gas permeation and temperature relationship @ 1.5 barg. 


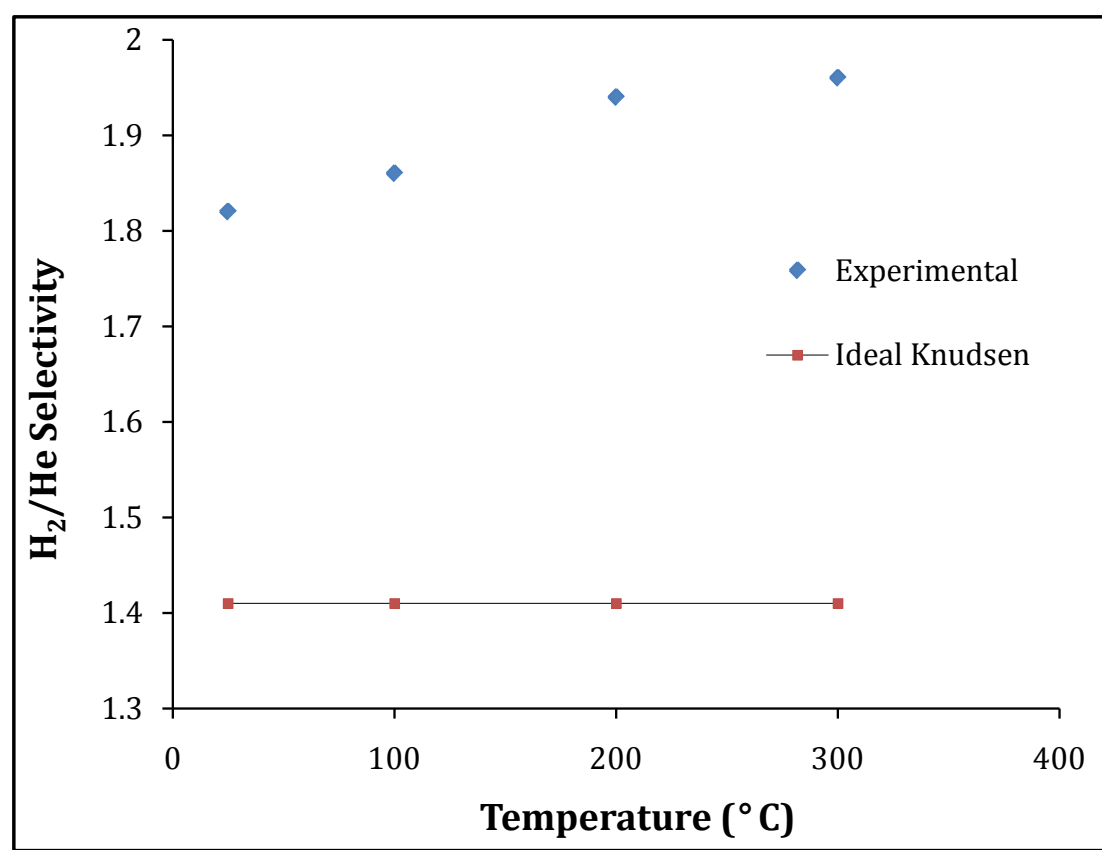

Figure 5. $\mathrm{H}_{2} / \mathrm{He}$ Selectivity and temperature relationship on Pt membrane @ 1.6 barg.

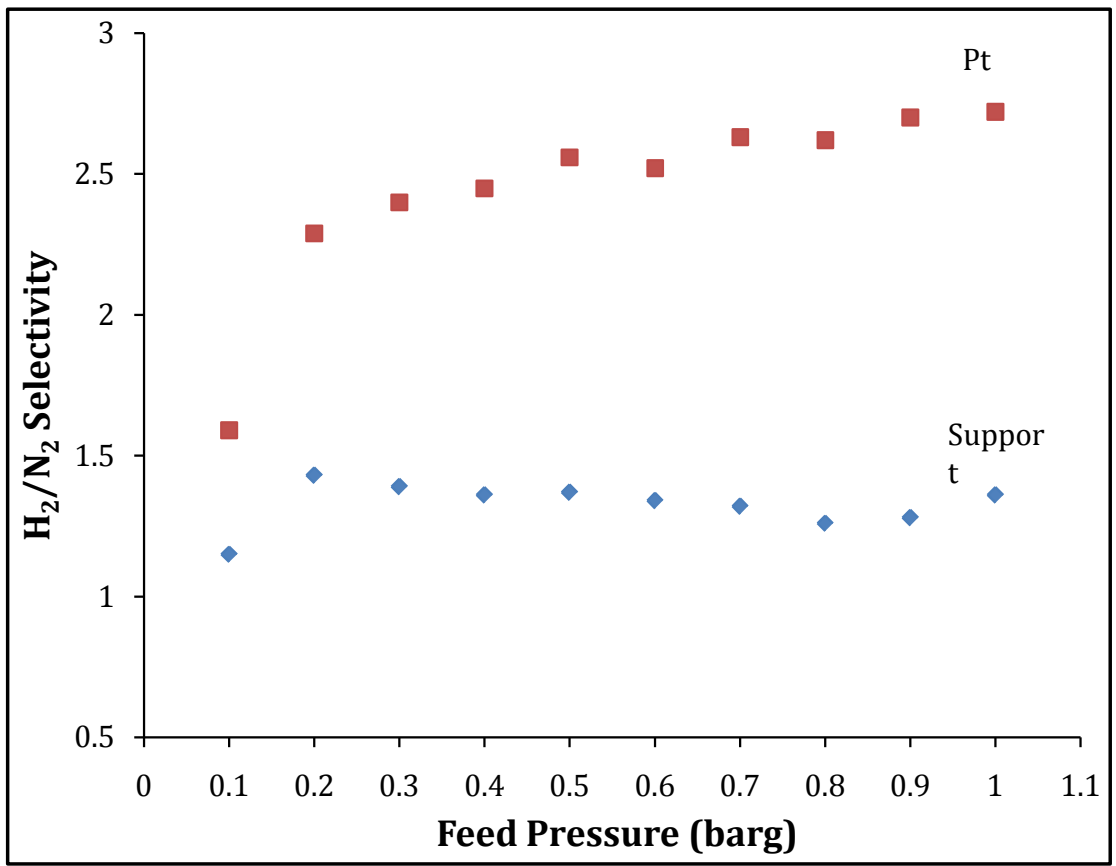

Figure 6. $\mathrm{H}_{2} / \mathrm{N}_{2}$ Selectivity and feed pressure relationship on support and Pt membrane (a) $25^{\circ} \mathrm{C}$.

\section{Conclusion}

Tubular commercially available support and Pt membrane were employed for $\mathrm{H}_{2}$ separation. Single gas performance through the support and Pt membrane showed Knudsen diffusion transport for the smaller molecular weight gases $\left(\mathrm{H}_{2}\right.$ and $\left.\mathrm{He}\right)$. On the other hand, transport of the larger molecular weight gas $\left(\mathrm{N}_{2}\right)$ was independent on temperature. The single gas permeation of $\mathrm{H}_{2}$ increased from 4.6 to $6.0 \mathrm{l} / \mathrm{min}$ in the temperature range $25^{\circ} \mathrm{C}$ to $300^{\circ} \mathrm{C}$, whilst the selectivity of $\mathrm{H}_{2} / \mathrm{He}$ and $\mathrm{H}_{2} / \mathrm{N}_{2}$ attained values of 1.96 at $300^{\circ} \mathrm{C}$ and 2.72 at $25^{\circ} \mathrm{C}$. $\mathrm{High}$ 
temperature also favoured $\mathrm{H}_{2}$ diffusion as the $\mathrm{H}_{2}$ selectivity increased by almost 2 folds as compared with the theoretical Knudsen selectivity.

\section{Acknowledgements}

The authors gratefully acknowledge Petroleum Technology Development Fund (PTDF) Nigeria for funding this research, and School of Pharmacy \& Life Sciences RGU Aberdeen for the SEM and EDXA results.

\section{References}

[1] Kanezashi, M. and Asaeda, M. (2006) Hydrogen Permeation Characteristics and Stability of Ni-Doped Silica Membranes in Steam at High Temperature. Journal of Membrane Science, 271, 86-93. http://dx.doi.org/10.1016/j.memsci.2005.07.011

[2] Sun, Y.-M. and Khang, S.-J. (1988) Catalytic Membrane for Simultaneous Chemical Reaction and Separation Applied to a Dehydrogenation Reaction. Industrial \& Engineering Chemistry Research, 27, 1136-1142. http://dx.doi.org/10.1021/ie00079a008

[3] Tsotsis, T.T., Champagnie, A.M., Vasileiadis, S.P., Ziaka, Z.D. and Minet, R.G. (1993) The Enhancement of Reaction Yield through the Use of High Temperature Membrane Reactors. Separation Science and Technology, 28, 397-422. http://dx.doi.org/10.1080/01496399308019497

[4] Chai, M., Machida, M., Eguchi, K. and Arai, H. (1994) Promotion of Hydrogen Permeation on Metal-dispersed Alumina Membranes and Its Application to a Membrane Reactor for Methane Steam Reforming. Applied Catalysis A: General, 110, 239-250. http://dx.doi.org/10.1016/0926-860X(94)80199-1

[5] Lewis, A.E., Kershner, D.C., Paglieri, S.N., Slepicka, M.J. and Way, J.D. (2013) Pd-Pt/YSZ Composite Membranes for Hydrogen Separation from Synthetic Water-Gas Shift Streams. Journal of Membrane Science, 437, $257-264$. http://dx.doi.org/10.1016/j.memsci.2013.02.056

[6] Bose, A.C. (2009) Inorganic Membranes for Energy and Environmental Applications. Springer, New York. http://dx.doi.org/10.1007/978-0-387-34526-0

[7] Howard, B.H. and Morreale, B.D. (2008) Effect of $\mathrm{H}_{2} \mathrm{~S}$ on Performance of $\mathrm{Pd}_{4} \mathrm{Pt}$ Alloy Membranes. Energy Materials, 3, 177-185. http://dx.doi.org/10.1179/174892309X12519750237717

[8] Bischoff, B.L. and Judkins, R.R. (2011) Development of Inorganic Membranes for Hydrogen Separation.

[9] Uzio, D., Miachon, S. and Dalmon, J.-A. (2003) Controlled Pt Deposition in Membrane Mesoporous Top Layers. Catalysis Today, 82, 67-74. http://dx.doi.org/10.1016/S0920-5861(03)00203-7

[10] Gopalakrishnan, S. and Diniz da Costa, J. C. (2008) Hydrogen Gas Mixture Separation by CVD Silica Membrane. Journal of Membrane Science, 323, 144-147. http://dx.doi.org/10.1016/j.memsci.2008.06.016

[11] Kajama, M.N., Nwogu, N.C. and Gobina, E. (2014) Hydrogen Separation Using Silica-Based Composite Membranes. Advanced Materials Research, 1051, 107-111. 